\title{
Elogio de la mujer que vota. El voto municipal femenino en Santa Fe, Argentina $^{1}$
}

IN PRAISE OF THE WOMAN WHO VOTES.

The municipal female vote in Santa Fe, Argentina

\author{
Adriana María Valobra \\ Centro Interdisciplinario de Investigaciones en Género, \\ UNLP-CONICET, La Plata, Argentina \\ http://orcid.org/0000-0003-3955-4791 \\ indivalobra@gmail.com
}

Resumen: La producción académica que incluye alguna referencia al sufragio municipal femenino en la provincia de Santa Fe es poca y lo hace de manera nominal. En este artículo, me propongo delinear los recorridos del sufragio municipal femenino en dicha zona. El ejercicio central es la visibilización y la reposición de algunas preguntas básicas, imprescindibles: qué, quién,

1 Quiero agradecer a Mariela Rubinzal la invitación a abordar el sufragismo santafesino, así como su lectura y comentarios a una versión inicial de este trabajo. A José Zanca, Verónica Giordano, Diego Mauro y Natacha Bacolla, los intercambios sobre el tema. A María Luisa Múgica, Maricel Bertolo, Paula Caldo, Viviana Bolcatto y Oscar Videla los sustantivos materiales compartidos y los comentarios sobre el tema, hubiera sido imposible sin su generosidad concluir la investigación durante la pandemia de COVID-19. A Graciela Queirolo, la lectura atenta de este artículo. A Santiago Pérez Valobra y Atilio Calivari, la asistencia técnica. A quienes realizaron los referatos por las sugerencias bibliográficas y comentarios enriquecedores. 
cuándo, dónde, cómo, para qué y por qué. Como hipótesis, pensamos que el cambio de escala y la mirada desde la perspectiva de género nos permitirá apreciar aspectos diferentes (Fernández, "La historia" 19) y "escribir una historia más diversa, heterogénea, distinta de la nación argentina" (Palermo "La historia" 32), que relativice el predominante "hecho nacional", incluidas las historias del sufragio femenino.

Palabras Clave: sufragio municipal, mujeres, Santa Fe, Argentina.

АвSTRACT: The academic research that includes any reference to Santa Fe's municipal female suffrage is scarce and nominal. In this paper, I propose to outline the routes of women's municipal suffrage in the province of Santa Fe. The central exercise is the visibility in order to answer basic, essential questions: what, who, when, where, how, for what, and why. As hypotheses, we propose that changing the scale from a gender perspective will allow us to see different aspects (Fernández "La historia" 19) and "write a more diverse, heterogeneous history, different from the Argentine nation" (Palermo "La historia" 32), which relativizes the predominant "national fact", including female suffrage's histories.

KeYwords: municipal suffrage, women, Santa Fe, Argentina.

\section{INTRODUCCIÓN}

La historia de las mujeres, así como también los estudios feministas, tempranamente se ocuparon del sufragismo femenino. Tanto en América como en Europa, las producciones son prolíficas ${ }^{2}$. El ámbito municipal fue un espacio central para el éxito de algunos grupos políticos de izquierda. También, algunos lo consideraban más adecuado para las intervenciones

2 Solo a modo de ejemplo se pueden mencionar dos de los mejores estudios sobre esa historia en Francia: Les filles de Marianne: Histoire des féminismes, 1914-1940 de Christine Bard y Les années Beauvoir (1945-1970) de Sylvie Chaperon. Sobre el sufragio femenino en América, nuevamente, la producción nacional es voluminosa para cada país. Un esfuerzo de integrar algunos casos nacionales se aprecia en Sufragio Femenino. Prácticas y debates politicos, religiosos y culturales en Argentina y América, editado por Carolina Barry. 
femeninas pues contaban con un mayor conocimiento del contexto, así como la oportunidad de aprendizaje para, a futuro, ejercer el sufragio en un espacio supuestamente menos conectado con su quehacer cotidiano como podía ser el nivel provincial o nacional ${ }^{3}$. En líneas generales, las historias del sufragio femenino tienden a equiparar el sufragio político (provincial o nacional) y el territorial o municipal, sin dimensionar los alcances electorales de esa legislación en países en los que esos sufragios pueden ser optativos y calificados. Las miradas más sociológicas, por su parte, suelen explicar la obtención del voto de manera invariable (origen latino, religión predominante protestante, mayor desarrollo socioeconómico), privilegian el momento de sanción de una ley para calificar un país, perdiendo el proceso de disputas, y, en general, tienden a unir la historia del sufragio con la de la democratización, tomando como referencia las "democracias occidentales", en cuyos parámetros América Latina se acomoda mal (Nohlen 58).

En Argentina, si bien hay un enorme caudal de investigaciones sobre el sufragio femenino, estas se orientan especialmente al estudio del movimiento por su obtención -concentrado especialmente en el núcleo de la capital de la nación- y, sin duda, se eclipsan ante el contexto de su sanción, el del peronismo. Por ello, no tienen tradición en preguntarse por el nivel municipal, el que es referido de manera colateral, espasmódica e incompleta en las historias del sufragio (Valobra, "Una historia"). El caso de Santa Fe resulta un desafío para la investigación y, asimismo,

3 Sobre el sufragio municipal en América Latina se han consignado distintos requisitos para la inclusión de las mujeres que tuvieron en cuenta o la propiedad o la contribución pecuniaria o la calificación por edad o por educación o todas ellas a un tiempo. Sin ánimo de exhaustividad, puede consultarse, sobre Ecuador, el artículo "Sufragio femenino en Ecuador (1884-1940)" de Mercedes Prieto y Ana María Goetschel; sobre Chile, los textos “"Rumbo a la Moneda': historia del movimiento sufragista en Chile, 1913-1952" de Claudia Rojas, "La municipalidad y la casa: roles de género en el debate sobre el sufragio femenino y los gobiernos locales en Chile (1910-1935)" de Camila Sanhueza, "Discursos En torno al sufragio femenino en Chile 1865-1949" de Javiera Errázuriz y "Sufragio femenino en Chile: origen, brecha de género y estabilidad, 1935-2009” de Miguel Ángel López y Ricardo Valenzuela; sobre Colombia, el artículo "La primera promulgación de derecho al voto femenino en Latinoamérica. Provincia de Vélez, Colombia, 1853" de Nathalie Goldwaser; y sobre México, el libro El debate sobre el sufragio femenino en la prensa tapatía (1946-1955) de Guillermo Castillo Ramírez. 
aguarda no solo la visibilización del derrotero del sufragio femenino municipal en cada momento histórico sino también la delimitación de problemas vinculados a la agenda de investigación.

Las pesquisas sobre el voto femenino municipal en la provincia de Santa Fe se encuentran en una relación inversa al gran cúmulo de investigaciones que, desde la historia política, se han desarrollado sobre el voto municipal en esa provincia. Sobre esto último, el estudio de Marcela Ternavasio resulta el de mayor envergadura. La autora reconstruye, desde mediados del siglo XIX hasta 1920, los debates sobre la institucionalización del municipalismo moderno (Ternavasio 3) que giraron en torno de si el nivel municipal debía funcionar como unidad política o administrativa, como ámbito de descentralización y/o autonomía respecto de un poder central, y de la definición del sujeto en torno a la elección y representación. Este último punto se define por la condición de contribuyente mientras que en el sufragio nacional y en el provincial se tomaba como base a la población masculina, a la que se le exigía el tributo de sangre, es decir, la defensa de la patria ante una guerra y la obligación del servicio militar para prepararse ante esa eventualidad. Así, se distinguieron dos modelos: el del municipio con comunidad, donde el sujeto político era el contribuyente, y el provincial o nacional, en el que el sujeto era el individuo ciudadano.

En efecto, la definición de quiénes podían elegir representantes en el marco de la ciudadanía territorial -sin contar con la ciudadanía política, por su condición de extranjería - fue clave en la historia provincial con alta inmigración -a fines del siglo XIX, el índice de masculinidad demográfica no solo era positivo, sino que, entre la población extranjera, se ubicaba en el 67\% (Bonaudo 174)-. Precisamente, uno de los principales conflictos devino de la exclusión de los extranjeros del universo electoral en 1890 y el otro, de la cantidad de habitantes que definían un municipio (Bonaudo 164-166). Esta discusión, entre otros factores, estuvo presente en uno de los movimientos políticos y sociales más estudiados de la historia santafesina, el llamado Grito de Alcorta, el surgimiento de la Liga del Sur y el Partido Demócrata Progresista (Malamud 211-238). Diego Roldán ha señalado cómo los elementos sociales y económicos del contexto bélico y postbélico luego de la Primera Gran Guerra hicieron del municipio un ámbito clave para llegar a los sectores más vulnerables de la recesión económica, a falta de destreza 
de los niveles provinciales y nacionales: "los reclamos por una aplazada modernización política irritaron los núcleos más sensibles de la legislación provincial, colocando en discusión las normativas provinciales que regían los municipios" (49). El sufragio municipal o territorial fue, por tanto, central en la Asamblea Constituyente de 1921 y también en su puesta en vigencia en la década del 30 . Recientemente, se ha discutido la centralidad que tuvo esta instancia entre la población inmigrante a fines de la década del 20, en contraste con lo demostrado para períodos anteriores (Videla 7-8).

A pesar de estos desarrollos investigativos, durante muchos años el voto municipal femenino en Santa Fe fue apenas una mención colateral, con fechas distintas, imprecisiones interpretativas y ausencias de fuentes primarias. Algunos documentales fílmicos realizaron un primer ejercicio de visibilización consignando que el voto municipal en Santa Fe era un hecho olvidado y mostrando testimonios de prensa y fotografías que permitían consignar el carácter pionero de la provincia en la historia nacional -como el documental Señora... puede usted votar de Sonia Helman-, aunque carecemos aún de una narrativa organizadora de los hitos en ese proceso y, asimismo, de respuestas para lo que algunos autores denominan las preguntas esenciales (Elder y Paul 5).

La provincia de Santa Fe, y en particular sus dos principales ciudades, Rosario y Santa Fe -la ciudad capital-, han sido leídas como parte de ese proceso modernizador, especialmente la primera (Megías; Cervera). El problema del sufragio municipal se inscribe en el discurso de la modernización política y el reformismo liberal que encontró en Santa Fe un caso anticipado de los sucesos nacionales (Macor, La reforma 10-11).

La producción académica que incluye alguna referencia al sufragio municipal femenino santafecino es poca y lo hace de manera nominal, sin profundizar en el entramado de relaciones de fuerzas políticas ni, de modo más amplio, en el modo en que la problemática de género se configura en las relaciones de poder. En este artículo, me propongo delinear los recorridos del sufragio municipal femenino en la provincia de Santa Fe. El mismo presenta, a mi modo de ver, tres momentos que serán desarrollados en los tres apartados siguientes. El primero remite al año 1921 y al contexto de la Convención Constituyente de la Provincia de Santa Fe, luego vetada por el gobernador. El segundo corresponde a la puesta en marcha de una reforma en la legislación municipal en 1927 , 
que efectivamente se implementa en Rosario y Santa Fe. El tercero es la puesta en vigencia de la Constitución de 1921 en el gobierno del demócrata progresista Luciano Molinas. Nos interesa un ejercicio menos ambicioso, pues entendemos que, en el estado actual de la investigación, no se puede pretender una teorización sin bases factuales que permitan una explicación. Por ello, el ejercicio es una visibilización que reponga preguntas básicas, imprescindibles: qué, quién, cuándo, dónde, cómo, para qué y por qué. Como hipótesis, pensamos que el cambio de escala y la mirada desde la perspectiva de género, permitirá apreciar aspectos diferentes (Fernández, "La historia" 19) y "escribir una historia más diversa, heterogénea, distinta de la nación argentina" (Palermo, "La historia" 32), que relativice el predominante "hecho nacional", incluidas las historias del sufragio femenino.

Las fuentes utilizadas son la prensa comercial de Santa Fe, los periódicos El Orden, El Litoral y Santa Fe-disponibles en la Hemeroteca Digital Fray Francisco de Paula Castañeda, Archivo General de la Provincia de Santa Fe-. Asimismo, se utilizarán los Diarios de Sesiones de la Asamblea Constituyente (DSAC) y normativas provinciales. Dadas las dificultades que existen con los materiales documentales, este trabajo avanza como un estudio inicial para presentar un mapa de los recorridos que se pueden establecer con las condiciones documentales existentes y, asimismo, abrir agenda de investigación.

\section{El voto FEMENino EN UNA CONSTITUCión PROVINCIAL Vetada}

$\mathrm{Al}$ iniciarse la década del 20, la provincia de Santa Fe se encaminó a reformar su Constitución que databa de 1900 y que muy tempranamente había incorporado el voto universal masculino y secreto, algo que recién en 1912 sería alcanzado en el nivel nacional (Macor y Piazzessi 233). Las transformaciones de la provincia requerían una legislación acorde al momento histórico. El proceso de urbanización, el aumento demográfico, la complejización de las relaciones sociales y económicas, así como la dinámica de la política, se inscribieron en lo que los estudios consideran un proceso de modernización. Los dos partidos mayoritarios, el Partido Demócrata Progresista (PDP) y la Unión Cívica Radical (UCR), impulsaban esa reforma constitucional (Mauro 21-22). La llegada al 
poder nacional de la UCR no pudo ocultar, sino más bien exacerbó, las tensiones internas del partido en el nivel provincial y entre esas jurisdicciones, lo que generaría una alta conflictividad no solo con otros partidos sino especialmente con los propios correligionarios y, en menor medida, con el PDP, que no lograba convertirse en una fuerza de arrastre local ni mucho menos nacional (Macor y Piazzessi 233). Al momento de la Convención Constituyente en la provincia, el gobierno estaba encabezado por el radical Enrique Mosca (1920-1924), y la Convención fue presidida por el también radical Manuel Menchaca, quien fuera el primer gobernador electo de Santa Fe (1912-1916), bajo imperio de la Ley Sáenz Peña. Como señala Ana Persello, "a los factores de conflicto que tensionaban el partido, entre ellos la tradicional disputa norte-sur y las pujas facciosas por la ocupación de espacios de poder, se sumó la decisión de impulsar la reforma de la Constitución" ("Los gobiernos" 268), que terminó desgajando las fuerzas de seculares y religiosos con la impactante movilización popular católica que acarreó (Mauro 11-12). La espectacularidad del conflicto con la Iglesia católica, que reaccionó al considerar minado su poder en las propuestas de laicización del Estado del proyecto de la mayoría, opacó otras discusiones que venían de largo tiempo y que tuvieron en el centro la reforma electoral municipal. Respecto de esto último, un proyecto reclamaba representación por habitante; el otro, por ciudadano. El primero conllevaba que la zona sur de la provincia, la más poblada y con más extranjeros, tuviera mayor injerencia en los asuntos provinciales.

Entre esas discusiones se incluyó la del voto de las mujeres en el nivel municipal, el más mencionado -aunque no analizado, puesto que luego quedó plasmado en la norma-. Sin embargo, este es un dato incompleto ya que, además de proyectos de voto municipal, hubo tres proyectos para el nivel provincial presentados por distintas fuerzas políticas. Me interesa subrayar este punto por dos razones. En primer lugar, por la desconsideración que ha merecido, al punto de que no hay quien recupere siquiera la referencia. Y, segundo, debido a que es distinta la definición de los sujetos en el marco municipal y provincial.

Los proyectos provinciales fueron impulsados por Antonio Cafferata, Carlos Lagos y Víctor R. Pesenti. Uno de ellos fue el del convencional constituyente por el departamento de Iriondo, Antonio Cafferata (18751932), reconocido abogado católico que en ese momento integraba el 
Partido Demócrata Progresista. Este convencional propuso tres artículos para la nueva Constitución. El primero consignaba: “Tendrán voto en las elecciones provinciales, previa inscripción en el Registro Electoral, las mujeres argentinas que hayan cumplido la edad de veintidós años, cualquiera que sea su estado civil y siempre que sepan leer y escribir". (DSAC LXIX). Lo tendrían también las extranjeras que además de aquellas condiciones, hubieran "contraído matrimonio con un argentino, de acuerdo a las leyes de la república" (ibid.). Luego, lo hacía extensivo al nivel municipal en las mismas condiciones y, finalmente, contemplaba que, una vez inscriptas en el registro electoral, "podrán también ser elegidas para desempeñar los cargos de senadores y diputados provinciales y miembros de los Concejos Deliberantes municipales en las mismas condiciones de los hombres que puedan desempeñar tales cargos" (DSAC LXX).

Un segundo proyecto fue el de Carlos Lagos, un dirigente reconocido del demoprogresismo, perteneciente a la elite rosarina, hijo del fundador del diario La Capital, Ovidio Lagos. El capítulo I "Incorporación de la mujer a las actividades de la vida política de la provincia” establecía cuatro artículos por los que se acordaban "todos los derechos y garantías del ciudadano argentino" (DSAC LXX); y la edad de ciudadanía sería la misma que la del varón argentino (18 años). El capítulo II requería para la mujer "sufragante y elector" [sic], que supiera leer y escribir. A las extranjeras, además de saber leer y escribir, se les exigía diez ańos de residencia en el territorio o cinco en la provincia. También consignaba que podrían ser electoras y elegibles "para los puestos públicos, legislativos y judiciales" (ibid.). Sin embargo, no se consideraba que pudieran ejercer cargos ejecutivos salvo que cumplieran con ciertos requisitos: si eran solteras y nacidas en territorio argentino, debían tener 25 años y 35 en caso de ser extranjeras; las casadas y nacidas en territorio argentino podían ocupar la Cámara de Diputados con 22 años y el Senado con 30. Las extranjeras debían contar con las mismas edades y la residencia (DSAC LXX). Como requisitos, a la edad se sumaban la lectoescritura y "una renta de mil pesos anuales obtenida en sueldos de profesiones educacionales o en renta de bienes muebles o inmuebles, administrada personalmente" (DSAC LXXI). Las extranjeras debían cumplir con los mismos requisitos y el período de residencia. A las mujeres que tuvieran "un título profesional emitido por universidad nacional o extranjera que hubiera revalidado en la república" (DSAC LXXI) no se les exigiría "tener 
renta”, así como tampoco se exigiría a las que tuvieran más de un hijo. Lo mismo aplicaba para las viudas. Para ser miembro del Poder Judicial, las mujeres debían contar con título de abogacía emitido por una universidad nacional o extranjera revalidado en Argentina, superar los 30 ańos, haber nacido en Argentina, tener cinco años de ejercicio en la profesión y mil pesos de renta anual -algo muy excepcional de que sucediera si se tiene en cuenta que, en las primeras décadas del siglo XX, eran menos las universitarias que se orientaban al derecho (Gómez Molla 4)-. En un registro especial se inscribirían las mujeres para ejercer sus derechos y no necesitarían la venia parental ni tutelar (DSAC LXXI).

Finalmente, Víctor Pesenti (1887-s/d), periodista, jurisconsulto y educador originario de Entre Ríos, legislador y convencional a comienzos de siglo, estaba vinculado a los círculos de librepensamiento de Rosario y era cercano a Manuel Menchaca (Abad de Santillán, s/p). Su propuesta estipuló que podrían votar en las elecciones provinciales las mujeres que poseyeran título o diploma provincial o nacional de cualquier profesión liberal, las que fueran cabeza de familia y las mayores de edad integrantes de sociedades comerciales inscriptas (DSAC LXIX).

Mientras que Cafferata y Lagos establecieron edades para las votantes, Pesenti solo consignó la mayoría de edad para las que tuvieran sociedades comerciales. Lagos estableció criterios de edad, educativos, profesionales y recursos para otros cargos legislativos, ejecutivos y judiciales. Cafferata, por su parte, consideró la accesibilidad a cargos no ejecutivos y Pesenti no incluyó ninguna de esas posibilidades.

En relación con los proyectos municipales, hubo dos más. Uno elaborado por los doctores de larga trayectoria militante en el radicalismo, así como en la docencia universitaria: Agustín Araya (1876-1936) y José A. Gervasoni, ambos de la UCR. Estos consideraban organizar los municipios según categorías por número de habitantes y delimitar según ello las funciones que tendrían y el tipo de cuerpo que tomaría su dirección. Los municipios de primera y segunda categoría - de mayor número de habitantes- podrían conceder "previa consulta al electorado, el derecho de voto a las mujeres argentinas y extranjeras esposas de extranjeros que puedan votar" (DSAC LX). Esta fórmula -ya adoptada en Uruguay en 1917- suspendía la decisión política a futuro y supeditaba su instrumentación a una serie de requisitos que podían arrojar resultados heterogéneos 
toda vez que, mediante un plebiscito, algunos municipios podían aceptar extender esa facultad y otros no.

El proyecto municipal que incorporó el sufragio femenino sin remilgos fue el presentado por Francisco Correa (1879-1935), dirigente de larga trayectoria en el demoprogresismo y reconocida presencia en la política provincial y nacional. En su proyecto se establecía que el cuerpo electoral se conformaría "por los electores provinciales; los extranjeros contribuyentes por la cuota que fijan las respectivas cartas y leyes orgánicas, las mujeres mayores de edad que tengan la libre administración de sus bienes o sean contribuyentes o ejerzan alguna profesión liberal" (DSAC LVI). No había referencia expresa al ejercicio de funciones en el Consejo Deliberante.

No obstante, en el estado actual de la documentación no se pueden reconstruir en profundidad los debates ${ }^{4}$. Por ello, hemos recurrido a otros estudios y documentos que introducimos a continuación.

Por entonces, recordemos, no había voto en la jurisdicción provincial en la Argentina y solo se contaba con el precedente del voto municipal en San Juan y el de Julieta Lanteri, tras litigar por su obtención en la ciudad de Buenos Aires y efectivizado solo en noviembre de 1911. En ese contexto, algunos convencionales apoyaban, desde tiempos muy tempranos, el voto político y territorial sin remilgos y en absoluta igualdad entre varones y mujeres. Era el caso de Luis Bonaparte (1853-1935), un librepensador que ya en 1904 se había manifestado a favor del feminismo (Bolcatto 76-77) y había defendido no solo la formación de las mujeres en el Congreso de Librepensamiento de 1906, sino también su sufragio equiparado al varón. Desde entonces, tenía comunicación con la líder socialista y sufragista Alicia Moreau de Justo, con quien mantuvo intercambios epistolares durante el desarrollo de la Asamblea Constituyente a fin de consolidar los argumentos a favor del voto político femenino (Bolcatto 321-322). En la biografía de Bonaparte es posible visualizar su intervención en el debate parlamentario: creía en el carácter propedéutico del voto y en la capacidad de saneamiento político que propiciaría el de las mujeres, además de apoyar sin remilgos que votaran tanto en el nivel municipal como provincial en nombre de la igualdad (Bolcatto 325).

4 El único tomo disponible actualmente de esa Convención reúne los proyectos introducidos, la presentación de diplomas de los constituyentes y primeros debates en torno al preámbulo. La prensa consultada hasta el momento retoma solo una parte de los debates, sobre todo los vinculados a la laicidad. 
Estas ideas fueron contrapuestas a otras que sobrevolaban. Por un lado, los medios locales consignaban cierta preocupación:

El ambiente en general dentro de los constituyentes es favorable a ese proyecto y casi puede asegurarse que tendrá mayoría salvo que se crucen observaciones de orden fundamental, como las que suelen oponerse a ciertas carreras liberales, la de escribano público, por ejemplo, en la que se observa que la mujer no puede dar fe por la conocida prescripción del código civil sobre las venias que deben acordar los padres o esposos para el ejercicio de ciertos derechos civiles ("El voto de la mujer en el orden provincial" primera plana).

Por otro lado, se consignaba la extendida idea de que, por la formación y el estado social de las mujeres, su voto pudiera orientarse atávicamente. Por ello podría haber sido apoyado por representantes católicos, como fue el caso de Antonio Cafferata ("El Dr. Cafferata propicia el voto a las mujeres" s/p), sin embargo, lo cierto es que tuvo apoyos disímiles. También hubo voceros individuales -como el reconocido abogado, juez y periodista Juan Álvarez ("La reforma del régimen municipal” s/p) - y colectivos -como el "Comité Popular pro reforma a la Constitución para solicitar a la Convención”- que reclamaron el reconocimiento de aquellas facultades a las mujeres (Bolcatto 318). No obstante, hasta el momento no se ha detectado ningún grupo sufragista local exclusivamente de mujeres como sucedía en otros ámbitos, lo que deja abierta la agenda de investigación.

A través de esos indicios podemos saber que el debate evidenció que las distintas posiciones partidarias no eran contradictorias con la idea del voto femenino en el nivel municipal y que, además, algunas posiciones impulsaron el voto femenino provincial sin que se contrapusieran por ello con posturas manifiestamente religiosas. La sanción final consignó, en el inciso 1 del artículo 36, que para las elecciones provinciales solo se consideraría a "los ciudadanos argentinos mayores de diez y ocho años que se hallen inscriptos en el registro cívico provincial", vale decir, varones. Mientras que, en el régimen municipal, "los extranjeros y las mujeres serán electores y elegibles para los cargos de carácter local, en el modo y forma que la ley o las respectivas cartas municipales determinen". Se aclaraba, en el artículo 144, que las mujeres debían ser "mayores de 
edad que tengan la libre administración de sus bienes o diploma que las habilite para ejercer alguna profesión liberal" (Blando y Defante 200, 218).

Las contradicciones de aquella norma finalmente sancionada en 1921 se mostraron prontamente solo para el ámbito municipal: una mujer argentina podía darle el derecho a su esposo extranjero a votar en el nivel municipal, pero no podía ella misma hacerlo si no tenía la libre administración de sus bienes o el diploma para ejercer profesión liberal. Esas profesiones remitían a tareas intelectuales que se desarrollaban, en general, de manera autónoma y requerían de un título universitario, algo que estuvo asociado a la idea de mujer moderna (Queirolo y Zárate 11, 14-15). Pero, salvo acuerdo prematrimonial, las mujeres no podían administrar sus bienes, algo que la ley de matrimonio civil y el Código Civil -ambos de alcance nacional- habían prefigurado y, al hacerlo, desconocieron la autonomía al adquirir el vínculo nupcial (Giordano, Ciudadanas 61; Queirolo 138-139). Asimismo, resulta interesante mencionar que es flagrante la exclusión de las maestras de ese derecho, tomando en cuenta que la huelga docente de 1921 las había tenido como protagonistas de la escena política no solo en las urbes sino en los espacios más alejados geográficamente, donde las maestras se convertían en referentes intelectuales y políticos (Pellegrini Malpiedi 299) ${ }^{5}$. Con todo, esta Constitución no llegó a aplicarse. La confrontación con el universo católico sumada al abandono de las sesiones y la propia tensión entre los radicales supusieron que la Asamblea Constituyente no llegara a dictar la norma dentro de los noventa días establecidos originalmente $y$, aunque en el entendimiento de su capacidad soberana, ella misma prorrogara el plazo, se desconoció esa posibilidad y la norma fue vetada por el gobernador radical, Enrique Mosca (1920-1924), bajo la presión del gobierno nacional.

\section{Voto femenino en la Ley Orgánica Municipal (i927)}

En febrero de 1927, las mujeres obtuvieron el voto político provincial a través de la Reforma Constitucional propiciada por el gobernador Aldo Cantoni -originariamente militante socialista y luego fundador,

Este aspecto ha sido abordado para otras regiones por Billorou, Vignoli y Fiorucci, entre otras referencias. 
junto a su hermano Federico, de la Unión Cívica Radical Bloquista-. En Santa Fe, luego de las conflictivas situaciones vividas tras el veto de la Constitución y el avance logrado por la democracia progresista, hacia 1923 se "impulsó la reunificación de las filas, quedando fuera solo un pequeńo núcleo liderado por Menchaca que levantaba la bandera de la Constitución de 1921. Ricardo Aldao, un radical 'nuevo' vinculado al clero, asumió el Gobierno y concluyó encolumnándose con el antipersonalismo" (Persello 268), es decir, convirtiéndose en opositor del expresidente Yrigoyen.

Las reformas del régimen municipal se inscriben en la lógica del interjuego de las fuerzas políticas y la dinámica electoral (Macor, "Sociedad" 245-246; Videla 2-3) así como en la adaptación entre legislación municipal y transformación social (Roldán 48). Tras la frustrada reforma que proyectaba la Constitución de 1921, fue durante la gestión de Aldao que se incluyó el sufragio femenino municipal, al sancionarse una nueva Ley Orgánica de Municipalidades -la Ley 2147 de septiembre de 1927-. Él mismo justificó su sanción en el último mensaje de apertura de sesiones que dio a la Legislatura provincial: "Instituido el voto universal, las ramas deliberativas de las municipalidades serán en lo sucesivo la expresión de mayorías reales" ("El gobernador envió ayer" 2).

La visión era idílica teniendo en cuenta que muchos habían denunciado fraude y violencia política en las elecciones de noviembre de 1927 y que, asimismo, Aldao no había logrado cuórum para el inicio de sesiones ("Fue una parodia insolente" s/p). De todos modos, algunos sectores recibían con cierto entusiasmo la implementación de la Ley 2147 toda vez que, aunque reconocían imperfecciones, consideraban que sería un instrumento para "sacudir la indiferencia ciudadana y [...] estimular el interés por el bien público, mejorando de ese modo notablemente la práctica del régimen representativo", subrayándose la importancia de la incorporación de las mujeres en la lógica no solo para ellas, sino como hito fundamental de la ampliación de la decisión del pueblo en la instancia municipal ("146 candidatos disputarán" 2; "Las elecciones de hoy" 3). La misma había tenido vaivenes debido a que había sido vetada por el gobernador, pues se habían dado plazos mayores para los cargos electivos que los que admitía la Constitución provincial, lo cual requirió revisiones de la comisión legislativa y nuevas presentaciones y 
pedidos para su tratamiento, realizados expresamente por Aldao ante la legislatura entre mayo y junio de 1927.

Videla visualiza esa reforma como parte de "las novedades institucionales que supone la ampliación del sufragio que pasa de un modelo fiscal sostenido en la figura del contribuyente urbano a otro de voto 'universal'" (Videla 3). Precisamente, la expansión de los votantes a nivel municipal es la expresión de la implementación de esta Ley Orgánica de Municipalidades. Es esta la que introduce nuevamente el sufragio femenino y, hasta hace poco tiempo, no era tematizada en las investigaciones (Videla; Giordano, "The fight"; Valobra "Una historia"). Las condiciones de la ampliación a las mujeres que se estipulaban en el artículo 57, Capítulo VII, del Régimen Electoral requerían que tuvieran

[...]: 22 años de edad [...] y títulos universitarios que las acrediten para ejercer una profesión liberal; las profesoras normales nacionales de segunda enseńanza y las que paguen impuestos a su nombre en comercios honestos, por una cantidad mayor a cincuenta pesos anuales (Diario de Sesiones de la Cámara de Diputados de Santa Fe -DSCDSF- 141).

Como señala Videla (8), a las mujeres se las excluía del ejercicio de cargos, aunque el de Intendente tampoco fuese electivo sino designado por el gobierno provincial, lo que era un punto de desacuerdo entre el PDP y el partido oficialista ("La reforma a la ley" primera plana). En los debates, no faltaron quienes señalaran que lamentaban que el gobernador no hubiera extendido el veto de la ley "hasta el voto de las mujeres que acuerda este proyecto", tal como expresó el diputado Plácido C. Lazo, del radicalismo unificado, retrucado por el demócrata progresista Ricardo Argonz y el radical unificado Pío Pandolfo, pero sin extensas confrontaciones (DSCDSF 141).

Aunque Aldao inscribiera la reforma en el orden del voto universal, es decir, como una ampliación de los sujetos de ciudadanía, el sufragio municipal no se encontraba en ese conjunto toda vez que continuaba siendo censitario y agregaba requisitos profesionales para las mujeres, excluyéndolas de la posibilidad de ser electas.

Para Videla, la cantidad de mujeres que participaron en las elecciones en Rosario fue muy baja, lo que expone 
el rotundo fracaso de la participación femenina; evidentemente no se inscribieron mujeres, pero también es evidente que los partidos no tuvieron ninguna política concreta para alentar su participación, es más, podría indicarse que tampoco la prensa local insistió en demasía sobre el asunto (8).

En efecto, el número que consigna Videla sobre las inscriptas en el padrón de Rosario fue, para 1927, de 28 mujeres, sobre un total de 54.642 personas; y de 70, sobre un total de 56.171, en 1929.

Lo interesante, en todo caso, es abrir la reflexión a la comprensión de la cultura política en clave de género y en relación con las lógicas imperantes. Entre otros aspectos que pueden explicar esa baja actuación se encuentran el poco tiempo entre la sanción de la ley y el período de inscripción en el registro electoral municipal, lo que pudo haber atentado para esa concurrencia teniendo en cuenta que se trata de un colectivo que se estrenaba en esas lides y que, para ello, requería contar con un conjunto de documentación y tiempo disponibles para reunirla y efectivizarla, amén de que se dudaba de cuántas mujeres cumplían aquellos requisitos ("Régimen Electoral Municipal" 6). Según la prensa, en algunos distritos las distintas elecciones de esos años se habían caracterizado por el absentismo, una indiferencia del electorado que no creía en cambiar el estado de situación con su voto ("Los comicios de ayer" 3; "Borratinas" primera plana; "El total de votantes" primera plana). Además, la ley dejó de lado la elección por candidato, e introdujo la lista, aunque manteniendo las borratinas -es decir, la posibilidad de borrar al candidato indeseado- (Persello 108), modificación que se entendía contraria al "sentir colectivo" ("Los comicios de ayer" 3).

Si bien los datos censales provinciales permiten apreciar que el número de mujeres alfabetizadas era elevado, la delimitación profesional para votar excluyó a un buen número de ellas. No es menor que la calificación circunscriba, entre otras, a profesionales liberales de las que debe consignarse que, a nivel nacional, entre 1900 y 1925 hubo 17.359 varones egresados de universidades nacionales y apenas 3.207 mujeres en todo el país, concentrándose muchos casos en la ciudad de Buenos Aires (Gómez Molla 13). También se detecta un buen número de propietarias y contribuyentes, pero no es claro cuántas alcanzan la renta requerida para el ejercicio electoral -un requisito que muchos extranjeros no lograban, como menciona la prensa-. En este sentido, 
cabe señalar el comentario que los medios espetaron ante la propuesta limitada para las mujeres: "Si bien adopta el voto universal para los argentinos como electores a concejales, en cambio, al otorgar el voto a la mujer lo restringe de tal manera que en la Capital no podrán inscribirse ni siquiera una docena" ("La reforma a la ley" primera plana). Luego de repasar los requisitos, el medio inquiría: “¿Cuántas pueden estar en tales condiciones?" (ibid.).

Por otro lado, si bien se sabe poco sobre la organización del sufragismo femenino local, sí se conocen algunas líderes y formadoras de opinión que exigieron estos derechos (Toledo Martínez 18), así como varones que hacían suyo el reclamo ("Feminismo" primera plana). Por ello, en efecto, es bajo el número de inscriptas, considerando que varios estudios consignan que las mujeres eran activas en Rosario y en Santa $\mathrm{Fe}$, donde se incorporaban a las dinámicas de la sociabilidad política y de los movimientos políticos (Fernández, "Olga"; Suárez), culturales (Múgica; Caldo y Fernández; Coudannes) y sindicales (Ascolani, "La huelga"). En ese marco, la prensa de las Escuelas Normales fue una caja de resonancia de las posiciones de las docentes respecto del tema:

Aunque la redacción del artículo respectivo y el debate previo a sus acciones revelan un pensamiento sin claridad mi vuelo de los escritores provinciales santafecino [sic] que pudo anotar el progreso institucional que marca la conquista del voto femenino en los comicios municipales (El Directorio 5).

Luego de observar el modo en que eran despojadas del voto político por imperio de las decisiones arbitrarias masculinas, las docentes señalaban:

asombra que hoy día en que nadie discute entre nosotros el dogma democrático de la soberanía del pueblo, se haya contradicho el derecho de la mujer diplomada a votar en las elecciones comunales de las ciudades santafecinas (ibid.).

Cerraban su diatriba con una reflexión contundente respecto de cómo entendían las decisiones de varones legislando sobre los derechos de las mujeres: creían que el artículo legal era tímido y confuso porque los hombres se proclamaban súbditos de las mujeres, pero querían "sin embargo no dejarla salir del vasallaje o de la condición de ilota en la 
vida pública, cuando ellos dictan leyes o deliberan sobre sus reformas" (El Directorio 5-6).

En ese marco, algunas notas locales y del ámbito nacional recogieron con buenos augurios los esfuerzos de las mujeres que se habían tomado el tiempo para la inscripción y para sopesar y elegir las candidaturas, ponderando el uso de la facultad que la norma les reconocía, desarrollando un "Elogio de la mujer que vota" ("Elogio" s/p)

\section{EL VOTO FEMENINO MUNICIPAL CON ENVERGADURA CONSTITUCIONAL}

Para 1927, ya existía una Constitución provincial que acordaba el voto a las mujeres y la posibilidad de ser electas en San Juan, primer antecedente consumado de tal participación y muy ventilado en los medios santafesinos, tanto a favor como en contra de ello ("En la provincia de San Juan" primera plana; "El voto femenino" primera plana). No obstante, la intervención decretada por el presidente Yrigoyen puso en jaque a la provincia sanjuanina anulando esa Constitución. Poco después, en el país estaría interdicta la democracia tras el primer golpe de estado cívico militar. Con la convocatoria a elecciones, un nuevo entramado político ubica al radicalismo -a una parte de él, al menos- en la abstención electoral, una forma de crítica a la prohibición de la candidatura del expresidente radical Marcelo T. Alvear y a la prisión de Yrigoyen, el presidente depuesto. Así, llega al gobierno nacional una coalición entre conservadores y radicales y, en la bancada legislativa, se suman las posiciones del socialismo. Las discusiones legislativas nacionales de los ańos 30 sobre el sufragio político femenino se caracterizan por la aparición de fuerzas conservadoras que lo impulsan en el nivel nacional y que esperaban arrebatarlo a la centroizquierda (Palermo, "El sufragio" 168 y 169; Valobra, Del hogar 33-34). Desde allí surgen grupos de laicas católicas a favor del voto calificado, como la Asociación Argentina del Sufragio Femenino, dirigida por Carmela Horne de Burmeister.

6 Sin título. 11 de noviembre de 1928, s/p. Fotografiaba a la esposa de Argonz y a Fanny Bannet de Wasch votando. La imagen de esta última también se replicó en Caras y Caretas ("Rosario" 1 de diciembre de 1928), donde se la presentó como "una de las más entusiastas partidarias del voto femenino" (76). 
La provincia de Santa Fe estuvo intervenida durante el gobierno de facto nacional y, con la convocatoria a elecciones, llegará a su fin el predominio del radicalismo como fuerza rectora de gobierno (Macor y Piazzessi 247). Según Macor y Piazzessi (ibid.), varios factores concurren para facilitar el ascenso del Partido Demócrata Progresista: la inhibición electoral del radicalismo, las estrechas relaciones del líder Lisandro de la Torre con el presidente militar José Félix Uriburu y el desmembramiento de la dirigencia radical, así como los mecanismos de exclusión que el gobierno nacional impuso sobre ella.

A comienzos de los años 30, se distingue en Santa Fe un núcleo de mujeres no solo movilizadas individualmente por sus derechos políticos, sino también organizadas colectivamente en la Agrupación Femenina pro derechos de la mujer. Asimismo, las redes interprovinciales se tejían con mayor intensidad y mujeres de agrupaciones de la ciudad de Buenos Aires viajaban con el fin de impulsar filiales y entablar vínculos con las agrupaciones sufragistas existentes ("Agrupación femenina pro derechos de la mujer" 2). Igualmente, en 1931, una reconocida educacionista santafecina, Carlota Garrido de la Peña, incitaba a las mujeres a participar de las luchas políticas haciendo uso de los derechos de la legislación comunal. Sin embargo, Carlota era crítica de la legislación, a la que consideraba "de sobra cautelosa" e "insuficiente" porque solo podían votar aquellas mujeres que tenían aportes impositivos, pero se excluía a una estudiante o modista que no los tenían o, incluso, y no sin cierto elitismo, se quejaba de que se dejaba de lado a la dama distinguida y la señora de la clase media que no eran profesionales, pero estaban "capacitadas por su moralidad y buen concepto social para ejercitar el voto, como también las mujeres mayores de edad" ("El voto de la mujer" primera plana) con la educación primaria completa. En fin, la educadora aspiraba a que las mujeres participaran "sin limitaciones [...] de las inquietudes de la democracia" (ibid.).

El contexto de movilización general ante los comicios provinciales de 1931 encontraba a las mujeres ágiles en las lides militantes. Así, Alcira Olivé le escribía a Nicolás Repetto para que le permitiera inscribirse en las filas de la Alianza del PDP y el Partido Socialista con el objetivo de, en su "carácter de obrera y de mujer cristiana" ("Una delicada postura" 2), sumarse al proyecto de dignificar a las mujeres y obreros, los "seres más indefensos de la sociedad” que creía que aquella Alianza podría 
resolver eficazmente (ibid.). Dirigentes sufragistas de la Capital Federal se acercaron en 1932 para impulsar filiales del Comité Pro Voto de la Mujer y conseguir adhesiones a la campaña por los derechos políticos femeninos que se debatía en la legislatura nacional ("El voto para la mujer" 3$)^{7}$, donde finalmente se obtuvo media sanción, pero nunca se trató entre senadores.

Por su parte, Luciano Molinas fue electo por la Alianza Civil -frente del PDP y el Partido Socialista- con un ajustado triunfo:

expresa territorialmente la oposición nacional a La Concordancia; por las dificultades económicas que caracterizan estos primeros años de la década; por la crisis que envuelve al radicalismo y el debilitamiento de la legitimidad que su no participación provoca en el sistema político, y por las dificultades del PDP para resolver el pasaje del tradicional rol de oposición al de gobierno (Macor y Piazzessi 248).

Su gestión proveerá autonomía institucional al poder judicial y legislativo y reconocerá garantías individuales y extenderá derechos, en particular, educativos.

Aun con esa conflictividad política expresada a lo largo de toda la gestión, Molinas reinstaló la Constitución de 1921 tras considerarse que era improcedente el fundamento del veto del gobernador Mosca, fundado en que los convencionales no podían prorrogar sus deliberaciones más allá del plazo previsto (Ley 2160 de 1932). En relación con el sufragio municipal, la instauración de la elección de intendentes de forma directa será una propuesta de democratización y saneamiento. Con estas transformaciones, el sufragio femenino municipal adquirió envergadura constitucional provincial. No obstante, observaciones como las que había vertido Garrido de la Peña también se hicieron sobre el empadronamiento de mujeres en esa nueva instancia, pues se impidió que las maestras se inscribieran, ya que, en sentido estricto, el artículo 57 de la ley municipal limitaba "el derecho a votar a las mujeres universitarias, profesoras normales y a las que paguen impuestos de comercio

7 El periódico Santa Fe acompañó con una interesante encuesta de opinión a distintas referentes femeninas de la provincia. “¿Qué opina Vd. del voto femenino?” Una interesante encuesta entre las damas santafecinas", septiembre y octubre de 1932. 
por valor de cincuenta pesos o más" ("La inscripción de mujeres en el padrón municipal” s/p), mientras que la Constitución del 21 consignaba textualmente: "las mujeres argentinas mayores de edad que tengan la libre administración de sus bienes, o diploma que las habilite a ejercer alguna profesión liberal" (ibid.). Y, aunque algunos creían que las maestras debían ser consideradas votantes pues "el sentimiento público" así lo entendía, no se interpretaba que estuvieran comprendidas en esos marcos (" $\mathrm{La}$ inscripción de mujeres en el padrón municipal" s/p). Se mantenían, asimismo, las tensiones entre la lógica de la ampliación de los derechos electivos territoriales y el menguado abanico de derechos civiles que se le reconocía a las mujeres: "Deberán inscribirse las mujeres argentinas, solteras o viudas, mayores de edad, con residencia inmediata como así las casadas que tengan la libre administración de sus bienes o diploma que le habilite para ejercer una profesión liberal, con residencia de un año" ("Es obligatoria la inscripción de mujeres" 2).

Tampoco podían votar las extranjeras, aunque tuvieran hijos o hijas argentinas y nada se decía si eran casadas con argentinos, aunque los extranjeros casados con argentinas podían ejercer el voto municipal. La Junta Central de Elecciones, en efecto, tenía que resolver varias cuestiones en relación con el empadronamiento de las mujeres y extranjeros, puesto que no se había votado el Reglamento Electoral Municipal y ello implicaba tecnicismos que incidían en el acto electoral, como la documentación para votar y los procedimientos para los votos impugnados ("Importante resolución de la junta central de elecciones" s/p).

Finalmente, las mujeres ejercieron los derechos electorales municipales el 11 de marzo de 1934 y lo hicieron como votantes y como representantes. El voto se efectivizó en mesas receptoras propias para mujeres y extranjeros cuyo padrón no estaba ordenado por orden alfabético, como en el caso del padrón electoral de nativos, sino por número de inscripción en el padrón. También se realizaron votaciones en la Junta Electoral al día siguiente de las elecciones, aduciendo distintas razones contempladas por la ley ("Nuestro fotógrafo sorprendió a un grupo de mujeres que se disponían a votar en la Junta Electoral" 2), aunque se generaron varios inconvenientes con esas elecciones complementarias.

En las listas para el Concejo, se ubicaron como quinta y sexta suplente por la lista del Partido Socialista Ethel Catela y María G. de Rodríguez ("Quince candidatos a concejales votarán mańana cada una de las 
agrupaciones que participan en la lucha” 2). La que resultó electa fue Julieta Levaggi de Ginocchio -docente de 42 años, casada con Enrique Domingo Ginocchio y madre de dos hijas- que se había presentado por un partido independiente en la comuna de Soldini (Garbin s/p).

En subsiguientes elecciones, el nuevo Reglamento Electoral estableció la obligatoriedad del voto femenino so pena de multa. Según la prensa, muchas electoras femeninas no querrían "en forma alguna que se conozca la edad de las mismas dado que deberán presentar ante la mesa la partida de bautismo o del Registro Civil correspondiente" ("Es obligatoria" 2), una idea propia del sentido común en materia de género y complejo con la edad. Las multas eran pecuniarias (entre 25 y 60 pesos) y también incluían arrestos de quince días, que eran difíciles de cumplir pues "en Rosario, fuera del Asilo del Buen Pastor, donde van solo determinadas presas, no hay cárceles de mujeres" ("El voto femenino" 2).

Este señalamiento exclusivo sobre las mujeres llama la atención si se tiene en cuenta que es un nuevo electorado todavía no afianzado en la gimnasia electoral. Sin embargo, la suya no distaba de una situación habitual en los varones que, aun inscriptos, tenían un porcentaje bajo de concurrencia electoral (en algunos casos había llegado al 39\%, apenas superando el mínimo permitido por ley) ("En la ciudad votó el 39\% del electorado"s/p).

\section{Consideraciones de trazo grueso}

El voto municipal abre algunas discusiones sobre las relaciones entre la dimensión normativa y conceptual del sufragio. Lejos de lo que muchos suelen considerar como un anacronismo, motivado por las preocupaciones del feminismo actual pero inexistente en épocas pasadas, el sufragio femenino municipal tenía una tradición intelectual alimentada, incluso, por algunas sufragistas que consideraban ese ámbito como el más indicado para que las mujeres comenzaran sus primeras actuaciones políticas. En los contemporáneos, se observa un núcleo discursivo que reproduce la idea de que la incorporación de las mujeres en ese ámbito fue un indicador de una modernización política, una forma de adaptar lo político a las transformaciones sociales y una manera de incluir a un 
grupo excluido, que tendría el mérito sanador o espurio de la política, y, a la vez, un modo de legitimar el sistema democrático.

Queda abierta la invitación a profundizar en cómo esa originalidad se expresó en discusiones sobre las relaciones de género y ciudadanía y los vínculos con otras temáticas, como la reflexión sobre los derechos políticos de los varones y las mujeres inmigrantes. El sufragio municipal era un sufragio condicionado por la clase puesto que, para ejercerlo, al menos había que ser propietario o contribuyente y, en el caso bajo estudio, para las mujeres se requirió la formación educativa. Esa inclusión, por lo tanto, no era universal, sino que tenía rémoras de viejas miradas sobre quiénes eran vecinos en las ciudades y estuvo en el corazón de los debates sobre posibles ampliaciones del concepto hacia uno más universal. En el período bajo estudio, empero, si bien la incorporación de las mujeres supuso un universo muy exiguo de votantes -tanto por las condiciones exigidas, que pocas cumplían, como por la cultura política que las abstenía - se tendió a visualizar la ampliación del nivel municipal bajo el prisma de la universalización y bajo la lógica de la reforma electoral nacional que había significado la Ley Sáenz Peña. Desde ese punto de vista, para no hacer una historia evolucionista del voto y comprenderlo en su contexto, alcance y significado, es clave preguntarnos cómo pensar el sufragio municipal en la lógica de la historia del sufragio, en general, $y$ del sufragio femenino, en particular. Si por un lado significa una equiparación de género en el ámbito municipal, por otro, así como el voto masculino territorial, supone un criterio de clases y educativo/profesional que, al calificar al sujeto político, está reñido con la lógica universalista.

Si bien no he pensado mi investigación desde la matriz de la interseccionalidad como agenda de investigación, algunos debates conceptuales actuales, con sus aportes y limitaciones, podrían potenciar ciertas discusiones no solo en términos de ciudadanización o derechos, sino también desde esa idea de interseccionalidad en tanto se articulan género, clase, nacionalidad, entre otros ${ }^{8}$. El período bajo estudio marca, en conjunto, un proceso de transformación de los criterios que hoy en día son distintos en el ámbito municipal. No obstante, al mirar los vaivenes respecto de la posibilidad de ser electa, que ya se potencia también en la delimitación de las votantes, cobra relevancia la estrecha interrelación

8 Remito a la reflexión crítica de Viveros Vigoya y Gelabert, en particular en lo referido a la tensión entre el enfoque de la interseccionalidad y la teoría feminista. 
entre derechos civiles y políticos, puesto que los segundos entraban en contradicción con la idea de incapacidad que presentaban las mujeres en lo civil -particularmente, las casadas-.

En el mismo orden historiográfico, la reflexión requiere profundizar tanto en procesos políticos como en los enlaces espaciotemporales. En relación con lo primero, si bien este trabajo intenta un ordenamiento mesurado de los hechos, también abre y potencia una agenda de indagación sobre los móviles más profundos y los fundamentos más acabados de la ampliación en los estatutos municipales. Asimismo, indaga sobre qué reflexiones suscitó el voto municipal de las mujeres en los debates constitucionales que resultaron, finalmente, en la reforma de 1927 y su actualización en los años 30 , con la puesta en vigencia de la Constitución de 1921. En ese camino, es clave no naturalizar el hecho de que se dejara de lado el sufragio político del nivel provincial.

Si la historia se lee como un proceso de luchas, todavía es necesario profundizar en el modo en que aquellas propuestas se dieron por tierra. En particular, podríamos hipotetizar si las calificaciones requeridas a las mujeres por ser mujeres no fueron desechadas por romper la idea de igualdad que suponía el precepto de "un hombre, un voto". Por otro lado, cabe consignar también que promover el sufragio provincial chocaba contra las especulaciones sobre el carácter conservador que tendría el voto de las mujeres supuestamente manejado desde el púlpito, ideas extendidas en todo el abanico político, incluido el prosufragista -aunque en este caso, asumían el riesgo que ello significaba en pos de la propedéutica que implantaba el voto-. Un tercer elemento que evidencia la mirada local es que las divisiones entre conservadores, liberales tradicionales y modernizadores no se ajustan a un caso donde elementos católicos insuflaron entusiastas el sufragio municipal y/o provincial sin cortapisas en épocas más tempranas que las que se dieron en el ámbito nacional. Del mismo modo, no se puede atribuir a una lógica partidaria exclusiva esa dinámica, puesto que todos los partidos impulsaron aquella normativa.

En ese sentido, las correlaciones que se han establecido respecto de las mayorías católicas y la menor propensión a la sanción de una ley del voto femenino en el que se incluiría Argentina (Bertocchi 540) deben ser matizadas al cambiar la escala de análisis. En este camino, entonces, es también interesante pensar cómo algunas lecturas maniqueas de las leyes electorales no parecen acertar en este caso. Vale decir, si la ley la 
impulsaban representantes de distintos partidos, ¿había cálculo político respecto de cómo se beneficiarían con su implementación? ¿La impulsó el radicalismo en el gobierno para conseguir el voto de las mujeres en su favor o simplemente para sanear una imagen de política fraudulenta? ¿O la proponían los opositores porque consideraban que con ese voto llegarían al poder? En ambos casos, ¿creían que las mujeres profesionales o contribuyentes que podían votar los elegirían por sobre las demás candidaturas? En todo caso, esas interrogantes reproducen el tipo de preguntas que se hacen respecto de la sanción del sufragio en San Juan o el ámbito nacional y resultan claramente simplificadoras no solo para esos casos, sino para este en particular, como hemos visto.

Una tarea pendiente para estudiar el sufragio municipal santafecino resulta la de trazar el mapa de las organizaciones sufragistas de las cuales apenas se ha visto un emergente en los ańos 30, pero que cabe inquirir si preexistieron en una sociedad que se ha caracterizado en la historiografía como activa, dinámica y profundamente movilizada. En este sentido, hasta el momento hemos visto más bien varones regulando la dinámica política de las mujeres y también hemos avizorado agrupaciones de librepensamiento cuya incidencia debería profundizarse, en tanto incluyeron voces masculinas acendradas en asumir una posición feminista. Algunas notas significativas podrían ser aportadas por las campańas y encuestas que la prensa y las organizaciones desarrollaron ante ciertos hechos puntuales, tales como el tratamiento legislativo del tema. Asimismo, resulta interesante profundizar en las interrelaciones que los movimientos tuvieron a lo largo de todo el país y el impacto de los casos que sancionaron las normativas de sufragio femenino, a fin de conocer cuál fue la recepción de la práctica efectiva que allí se desarrolló y las reflexiones que estimuló. En todo caso, necesitamos pensar si la lógica del sufragio femenino municipal estuvo vinculada a presiones de movimientos políticos, y, en ese caso, a cuáles y de qué modo organizaron sus demandas; o si circularon como formas de transformación desde arriba, en virtud de inscribir el proceso en otras transformaciones o una combinación de ambas.

Finalmente, el absentismo electoral es un fenómeno que requiere ajustar algunas hebras del entramado de la sociabilidad para entender la falta de concurrencia femenina a las urnas, que no fue menor a la masculina. ¿’Por qué las mujeres que podían votar no se sintieron motivadas a hacerlo, 
incluso, cuando pesaba la obligatoriedad? ¿Por qué no lo hicieron los varones tampoco? ¿Acaso la obligatoriedad del voto intentó, como han señalado algunos autores, imponer el sentimiento de ciudadanía y/o pertenencia al cuerpo político, pero fueron necesarios otros elementos que habilitaran esa posibilidad? ¿Las condiciones del sistema electoral y el sentido del voto en contextos altamente conflictivos, de vaciamiento de la agencia misma a través de prácticas fraudulentas, disuadieron de esa participación?

El diseño metodológico requeriría, en ese camino, de una profunda reformulación que permita establecer las vinculaciones entre unos ciertos objetivos y las estrategias de construcción de datos y delimitación del corpus documental pertinente. En ese sentido, la exploración documental exige, primero, ampliar la búsqueda y someterla a sistematización para no construir explicaciones sobre hechos dudosos. Luego, es posible pensar un refinamiento analítico que nos demanda una constante reflexión y apropiación crítica que otorgue espesor a nuestras intelecciones, creatividad y solidaridad en los intercambios y acceso abierto a materiales de archivo en un contexto restrictivo para la investigación como resulta ser el de la actual pandemia.

BiBLIOGRAFÍA

Abad de Santillán, Diego. Gran enciclopedia de la provincia de Santa Fe. Santa Fe, EDIAR, 1967.

"Agrupación femenina pro derechos de la mujer". Santa Fe, Santa Fe, 5 julio 1931, p. 2.

Ascolani, Adrián (comp.). Historia del sur santafesino. La sociedad transformada (1850-1930). Rosario, Platino, 1993.

. "La huelga de profesores en las escuelas normales: los directores, entre la adhesión y la denuncia (Santa Fe, Argentina, 1921)". Revista Educaçâo e Emancipação, vol. 12, № 3, 2019, pp. 13-37.

BARd, Christine. Les filles de Marianne: Histoire des féminismes, 19141940. París, Nouvelles Études Historiques, 1995. 
Billorou, María José. "Mujeres que enseñan no solo en las aulas. Docentes en el interior argentino en la primera mitad del siglo XX". Historia de la Educación. Anuario, vol. 17, jun. 2017, pp. 57-79.

Blando, Oscar M. y Oscar F. Defante, La Constitución de 1921. $L a$ verdadera Constitución progresista de Santa Fe. Rosario, Laborde editor, 2014.

Bonaudo, Marta. "Santa Fe moderna". Signos santafesinos en el Bicentenario. Darío Macor (comp.), Buenos Aires, Ministerio de Innovación y Cultura de la Provincia de Santa Fe y Consejo Federal de Inversiones, 2011, pp. 220.

"Borratinas y El total de votantes". Santa Fe, Santa Fe, 30 abril 1928, primera plana.

Caldo, Paula y Sandra Fernández. "La vida como pretexto. Una aproximación a la relación entre biografía e historia a partir del caso de Olga Cossettini, Santa Fe, 1898-1987”. Estudios del ISHiR, vol. 2, 2012, pp. 174-187.

Chaperon, Sylvie. Les années Beauvoir (1945-1970). París, Fayard, 2000.

Cervera, Felipe. La modernidad en la ciudad de Santa Fe, 1886-1930. Santa Fe, Colección Santa Fe, 2011.

"146 candidatos disputarán 11 concejalías en las elecciones de hoy". El Orden, Santa Fe, 29 abril 1928, p. 2.

Coudannes, Mariela. "Tradición y cambio social en dos regiones de América del Sur. Mujeres elquinas y santafesinas en la narrativa de Marta Samatán”. SudHistoria, No 3, 2011, pp. 1-22.

"Diario de Sesiones de la Cámara de Diputados de Santa Fe", 17 de junio de 1927, Santa Fe, Cámara de Diputados.

Elder, Paul y Linda Elder. La mini-guía para el Pensamiento crítico Conceptos y herramientas. s/l, Fundación para el Pensamiento Crítico, 2003.

El Directorio. "El voto femenino". Revista de la Escuela Normal de Profesoras Dr. Nicolás Avellaneda, Rosario, marzo de 1927, pp. 5-6.

"El Dr. Cafferata propicia el voto a las mujeres". Santa Fe, Santa Fe, 3 febrero 1921.

"El gobernador envió ayer a la legislatura el Mensaje correspondiente al último ejercicio". El Orden, Santa Fe, 10 de abril de 1928, p. 2. 
"El voto de la mujer en el orden provincial". Santa Fe, Santa Fe, 20 febrero 1921, primera plana.

"El voto de la mujer en los comicios municipales". El Orden, Santa Fe, 24 diciembre 1931, primera plana.

"El voto femenino". El Litoral, Santa Fe, 10 septiembre 1935, p. 2.

"El voto femenino". La Acción, Rosario, 9 de abril de 1928, primera plana.

"El voto para la mujer. Se encuentra en ésta la presidenta del Comité de la Capital Federal". Santa Fe, Santa Fe, 18 mayo 1932, p. 3.

"Elogio de la mujer que vota". El Orden, Santa Fe, 1 mayo 1928, s/p.

"En la ciudad votó el 39\% del electorado". El Orden, Santa Fe, 24 diciembre 1931, s/p.

"En la provincia de San Juan, y de acuerdo a la nueva Constitución, las mujeres participarán con su voto de la cosa pública”. Santa Fe, Santa Fe, 12 febrero 1927, primera plana.

"Es obligatoria la inscripción de mujeres en el padrón municipal so pena de multas o arrestos". El Litoral, Santa Fe, 12 abril 1935, p. 2.

"Es obligatoria la inscripción de mujeres en el padrón municipal so pena de multas o arrestos”. El Litoral, Santa Fe, 12 abril 1935, p. 2.

"Feminismo". Santa Fe, Santa Fe, 31 mayo 1922, primera plana.

"Fue una parodia insolente el acto de elección comunal". Santa Fe, Santa Fe, 29 noviembre 1927, s/p.

Fernández, SAndra. "La historia regional y local, y las escalas de investigación. Un contrapunto para pensar sobre desafíos historiográficos". Quinto Sol, vol. 22, No 3, septiembre-diciembre 2017, pp. 13-20. - "Olga Cossettini en el laberinto de la sociabilidad política santafesina (Argentina, 1937-1943)". Revista Brasileira De História Da Educação, vol. 15, 2015, pp. 171-199.

FiorucCi, Flavia. "Las escuelas normales y la vida cultural en el interior: apuntes para su historia". Intelectuales, cultura y politica en espacios regionales de Argentina (siglo XX). Flavia Fiorucci y Paula Laguarda (eds.), Rosario, Prohistoria, 2012, pp. 131-152.

Garbin, Enrique. "Julieta Lavaggi de Ginocchio". Argentina Centro de Medios Independientes, 30 junio 2012. Web. Visitado el 10 de enero de 2021. Disponible en: https://archivo.argentina.indymedia.org/ print.php?id=816675 
Gelabert, Tomeu. "Repensando la interseccionalidad desde la teoría feminista”. AGORA, vol. 36, No 2, 2017, pp. 229-256.

Giordano, Verónica. Ciudadanas Incapaces: La Construcción de Los Derechos Civiles de Las Mujeres En Argentina, Brasil, Chile y Uruguay En El Siglo XX. Buenos Aires, Teseo, 2012.

. "The Fight for Women's Right to Vote in Latin America. A Long and Winding Road". Texto presentado en el Simposio sobre la Segunda Ola de sufragismo internacional en Japón, India y América Latina, 10 abril 2019, Universidad de Estocolmo.

Gómez Molla, Rosario. "Universitarias argentinas. Desafíos para contarlas". Anuario del Instituto de Historia Argentina, vol. 18, №1, 2018, s/p.

Helman, Sonia. Señora, puede usted votar... Buenos Aires, Estudio Platea, 2010. Disponible en: https://www.youtube.com/watch?v=lZSH-jN6eA0

"Importante resolución de la junta central de elecciones". El Litoral, Santa Fe, 12 marzo 1934, s/p.

"La inscripción de mujeres en el padrón municipal". El Litoral, Santa Fe, 10 noviembre 1932, s/p.

"La reforma a la ley orgánica de las Municipalidades". Santa Fe, Santa Fe, 6 de octubre de 1926, primera plana.

"La reforma del régimen municipal". Santa Fe, Santa Fe, 3 de febrero de $1921, \mathrm{~s} / \mathrm{p}$.

"Las elecciones de hoy". El Orden, Santa Fe, 29 abril 1928, p. 3.

"Los comicios de ayer". El Orden, Santa Fe, 30 abril 1928, p. 3.

Macor, Darío y Susana Piazzesi. "Santa Fe política, 1910-1955". Signos santafesinos en el Bicentenario, Darío Macor (comp.), Buenos Aires, Ministerio de Innovación y Cultura de la Provincia de Santa Fe y Consejo Federal de Inversiones, 2011, pp. 225-267.

Macor, Darío. "Sociedad, ciudad y ciudadanía. 'Los fundamentos de lo político en el espacio provincial. Santa Fe, 1912-1946”". Revista de historia, vol. 5, 1995, pp. 245-254.

- La reforma politica en la encrucijada. La experiencia demoprogresista en el Estado provincial santafesino. Santa Fe, Estudios Cedehis-UNL, 1993. 
Malamud Carlos. "El Partido Demócrata Progresista: un intento fallido de construir un partido nacional liberal-conservador". Desarrollo Económico, vol. 35, No138, 1995, pp. 289-308.

Mauro, Diego. De los templos a las calles. Catolicismo, sociedad y política en Santa Fe (1900-1937). Rosario, Prohistoria, 2018.

Megías, Alicia. "Modernización y turbulencias políticas. Rosario en la segunda mitad del siglo XIX". Los desafíos de la modernización. Rosario, 1890-1930. Alicia Megías et al., Rosario, UNR Editora, 2010, pp. 9-31.

Múgica, María Luisa. Sexo bajo Control. La prostitución reglamentada. Rosario, 1900-1912. Rosario, UNR Editora, 2001.

Nohlen, Dieter. Sistemas electorales del mundo. Madrid, Centro de Estudios Constitucionales, 1981.

"Nuestro fotógrafo sorprendió a un grupo de mujeres que se disponían a votar en la Junta Electoral, por no haber podido sufragar ayer por diversas razones". El Litoral, Santa Fe, 12 marzo 1934, p. 2.

Palermo, Silvana. "El sufragio femenino en el congreso nacional: ideologías de género y ciudadanía en la Argentina (1916-1955)". Boletín Del Instituto de Historia Agentina y Americana, vol. 16 y 17, 1998, pp. 151-178.

"La historia de Argentina más allá de la nación". Quinto Sol, vol. 22, No3, septiembre-diciembre 2017, pp. 29-37.

Pellegrini Malpiedi, Micaela. "Huelgas, maestras y rumores. Una escena de mujeres en lucha a partir de un estudio de caso (Firmat, Argentina, 1921)". La Ventana, vol. 6, N49, 2019, pp. 283-316.

Persello, Ana. "Los gobiernos radicales". Signos santafesinos en el Bicentenario. Darío Macor (comp.). Buenos Aires, Ministerio de Innovación y Cultura de la Provincia de Santa Fe y Consejo Federal de Inversiones, 2011, p. 268.

. "La búsqueda de la 'buena' representación: los diferentes 'usos' de la proporcionalidad”. Estudios Sociales, vol. 43, 2012, 105-132.

"¿Qué opina Vd. del voto femenino? Una interesante encuesta entre las damas santafecinas". Santa Fe, Santa Fe, septiembre y octubre de $1932, \mathrm{~s} / \mathrm{p}$. 
Queirolo, Graciela. "La mujer en la sociedad moderna a través de los escritos de Victoria Ocampo (1935-1951)". Zona Franca, vol. 14, 2005, pp. 144-154.

Queirolo, Graciela y Zárate Campos, Soledad. Camino al ejercicio profesional. Trabajo y género en Argentina y Chile (siglos XIX y XX). Santiago, Ediciones Universidad Alberto Hurtado, 2020.

"Quince candidatos a concejales votarán mañana cada una de las agrupaciones que participan en la lucha”. El Litoral, Santa Fe, 10 marzo 1934, p. 2.

"Régimen electoral Municipal". Santa Fe, Santa Fe, 26 octubre 1927, p. 3.

Roldán, Diego. "Procesos políticos locales. El caso del Gobierno Municipal de Rosario (1915-1920)". Avances del Cesor, Año VI, №6, 2009, pp. 43-64.

"Rosario". Caras y Caretas, Buenos Aires, 1 de diciembre de 1928, p. 76.

"Sin título". Democracia, Rosario, 11 de noviembre de 1928, s/p.

Scott, Joan. "Social History and the History of Socialism: French Socialist Muincipalities in the 1890's". Le Mouvement Social, N¹11, 1980, pp. 145-153.

SuÁrez, Teresa. "Activismos sociopolíticos femeninos en la provincia de Santa Fe, fines siglo XIX-principios siglo XX". Revista de la Junta Provincial de estudios Históricos de Santa Fe, No 72, 2015-2016, pp. 155-179.

Toledo Martínez, Palmira. "El sufragio femenino". Santa Fe, Santa Fe, 1 de enero de 1924, p. 18.

"Una Delicada Postura de la Mujer en Medio de la Política". El Orden, Santa Fe, 13 de septiembre de 1931, p. 2.

Valobra, Adriana. Del hogar a las urnas. Recorridos de la ciudadanía politica femenina. Argentina, 1946-1955. Rosario, Prohistoria, 2010. . "Una historia para el voto femenino municipal en San Juan: problemas, conceptos, metodología”. Revista Electrónica de Fuentes y Archivos, vol. 11, 2020, pp. 294-316.

Videla, Oscar. "Elecciones, partidos y conflicto social a finales de los años veinte del siglo XX en Rosario (Argentina)". Secuencia, vol. 104, 2019, pp. 1-30. 
Vignoli, Marcela. "Dar el voto con total libertad y consciencia": Prácticas de sociabilidad de maestras y maestros en el "Círculo del Magisterio", Tucumán, 1882-1912. Estudios Sociales Del Estado, vol. 5, $\mathrm{N}^{\circ} 9,2019$, pp. 152-174.

Viveros Vigoya, Mara. "La interseccionalidad: una aproximación situada a la dominación”. Debate Feminista, vol. 52, 2016, pp. 1-17.

Recepción: 04-02-20 Aceptación: 31-05-20 